\title{
Prediction of Surface Roughness after Turning of Duplex Stainless Steel (DSS)
}

\author{
Osamah F. Abdulateef \\ Department of Automated Manufacturing Engineering / Al-Khwairzmi College of Engineering/ \\ University of Baghdad/Iraq \\ Email: drosamah@kecbu.uobaghdad.edu.iq
}

(Received 8 December 2020; Revised 4 January 2021; Accepted 19 January 2021)

https://doi.org/10.22153/kej.2021.01.001

\begin{abstract}
Feed Forward Back Propagation artificial neural network (ANN) model utilizing the MATLAB Neural Network Toolbox is designed for the prediction of surface roughness of Duplex Stainless Steel during orthogonal turning with uncoated carbide insert tool. Turning experiments were performed at various process conditions (feed rate, cutting speed, and cutting depth). Utilizing the Taguchi experimental design method, an optimum ANN architecture with the Levenberg-Marquardt training algorithm was obtained. Parametric research was performed with the optimized ANN architecture to report the impact of every turning parameter on the roughness of the surface. The results suggested that machining at a cutting speed of $355 \mathrm{rpm}$ with a feed rate of $0.07 \mathrm{~mm} / \mathrm{rev}$ and a depth of cut $0.4 \mathrm{~mm}$ was found to achieve lower surface roughness with, an increase in the cutting speed and feed rate with the increases of the surface roughness. In addition, an increase in the depth of cut was found to reduces the surface roughness. The outcome of this study showed that ANN is a versatile tool for prediction of surface roughness and may be easily extended with greater confidence to various metal cutting processes.
\end{abstract}

Keywords: Artificial neural network, cutting depth, cutting speed, feed rate, orthogonal array, taguchi method.

\section{Introduction}

Metal cutting is one of the most commonly utilized manufacturing processes, the improvement in the performance of these processes and productivity based on cutting parameters like cutting tool geometry, cutting conditions in addition to the tool material and workpiece is essential. The surface feature is an essential parameter for determining the performance of machine tools and parts. Therefore, achieving the required surface quality is of great importance for the practical behavior of mechanical parts. The surface roughness is a widely utilized indicator of product quality in terms of various parameters such as fatigue life improvement, tribological considerations, corrosion resistance, etc. Today, particular consideration is given to dimensional precision and surface finish in every manufacturing industry [1]. Thus, it is possible to consider the measurement and characterization of the surface finish as a predictor of machining efficiency. The mechanism of surface roughness creation is very dynamic, complex, and process- dependent. Variety of factors like cutting fluid, cutting parameters, and the hardness of the workpiece have been found to affect surface roughness in the turning process in different amounts [2].

Several studies on surface roughness of different materials have been performed; the optimal cutting conditions are calculated most of the time utilizing the "Taguchi method" and by combining empirical models with different optimization algorithms based on roughness and artificial neural network (ANN). Gokkaya and Nalbant [3] examined the impact of feed, spindle speed, and coating type on surface roughness with 
various spindle speeds. They finalized that surface roughness is inversely commensurate with the spindle speed. Nalbant et al. [4] examined the prediction of surface roughness considering process parameters in the operation of $\mathrm{CNC}$ turning. To predict the surface roughness, they utilized a neural network with regression models. They concluded that the estimation of surface roughness utilizing neural networks was consistent with regression models. The impacts of cutting parameters on surface finish when turning composite materials utilizing "Taguchi experimental design techniques" have been studied by Palanikumar and Karthikeyan [5]. They concluded that the approach studied may be utilized to research the impact of surface roughness with a 95 percent confidence level in $\mathrm{Al} / \mathrm{SiC}-\mathrm{MMC}$ composites. Javidi et al. [6] investigated the impact of feed rate and tool nose radius on maximum surface roughness. To evaluate optimum cutting conditions utilizing the "Taguchi method", Dave et al. [7] examined surface roughness in turned machine parts. They concluded that in machining processes, surface roughness has a significant effect. Lavanya et al. [8] developed a predictive model on the basis of "ANN" for the prediction of AISI-1016 surface roughness during orthogonal turning with $\mathrm{CBN}$ insert tool. The experiments of turning were performed at various process conditions utilizing full factorial design. Feed rate, cutting speed and depth of cut, were the input parameters while the surface roughness was the output variable. The obtained results concluded that ANN is dependable method, and it can be easily used to various metal cutting processes with higher confidence. Kant et al. [9] joined the ANN along with a genetic- algorithm (GA) for surface roughness prediction and optimization. Vaibhav and Sachin [10] investigated boring aluminum material on $\mathrm{CNC}$ machining taking into account spindle speed, feed rate, and depth of cut to get minimum surface roughness utilizing the "Taguchi method". They suggested that the most important parameters for surface roughness are depth of cut and spindle speed. Das et al. [11] investigated surface roughness in CNC turning taking into account feed rate, cutting depth, and spindle speed utilizing the "Taguchi method". The verification of these parameters was justified by utilizing "Taguchi method". Gupta and Kumar [12] examined surface roughness and material removal rate in turning operation utilizing the "Taguchi method", taking into account rake angle and nose radius of the tool, feed rate, spindle speed, and cutting depth. They finalized that surface roughness increases with feed rate. Sonali et al. [13] examined optimum machining parameters considering surface roughness on aluminum 6061. They concluded that feed rate, depth of cut, spindle speed, and nose radius had a significant effect on surface roughness. Dahbi et al.[14] researched turning 2017A aluminum alloy utilizing a $\mathrm{CNC}$ lathe machine to calculate different cutting parameters. Utilizing ANN, they investigated the cutting parameters and their impact on surface roughness. The formulated ANN network founded that the experimental result was in near agreement with the predicted results. Pawan and Misra [15] suggested an enhanced predictive model for DSS turned component surface roughness. The impact of different input cutting parameter namely feed rate, cutting speed, and approach angle are taken into account for the established model. The L9 orthogonal array on a turning machine with analysis of variance were utilized to examine the impact of process parameters on surface roughness. They concluded that the feed rate was the most important factor followed by cutting speed and approach angle. Joshy et al. [16] performed CNC turning operation on the material of aluminum alloy 7075 and the surface roughness was conducted by considering machining parameters like feed rate, depth of cut, and spindle speed. The optimization of the process was carried out utilizing "analysis of variance (ANOVA)". The prediction of surface roughness has been carried out utilizing the "feed-forward backpropagation ANN method". Suresh et al. [17] investigated the impact of cutting parameters on surface roughness creation in machining of Duplex Stainless Steel (DSS) with TiN coated carbide tool. Taguchi technique is utilized for optimizing the cutting parameters. L27 orthogonal array was utilized to conduct the experimental trials. The obtained results indicated that the surface roughness decreases with increase in cutting speed and low feed rate. Elsadek et al. [18] applied "ANN" and response surface methodology (RSM) predictive tools for predicting "surface roughness" on hard- turning of AISI H13 hot work steel.

It is noted from the above literature that many studies have been studied for different materials utilizing the ANN method to optimize surface roughness. Hence, the present study analyzes the effects of cutting speed, feed rate, and depth of cut on surface roughness Ra by developing ANN models during turning of DSS by utilizing an uncoated carbide insert tool. Firstly, process parameters influencing surface roughness were 
covered by utilizing the "Taguchi method". The experimental results are based on the design of the experiment that has subsequently been utilized for training the ANN model. Finally, experimental confirmations are carried out on the developed model, and comparisons are made between experimental and predicted results of ANN.

\section{Methodology}

\subsection{Experimental Procedure}

In the present work, the used workpiece material is DSS bar of $300 \mathrm{~mm}$ length and $50 \mathrm{~mm}$

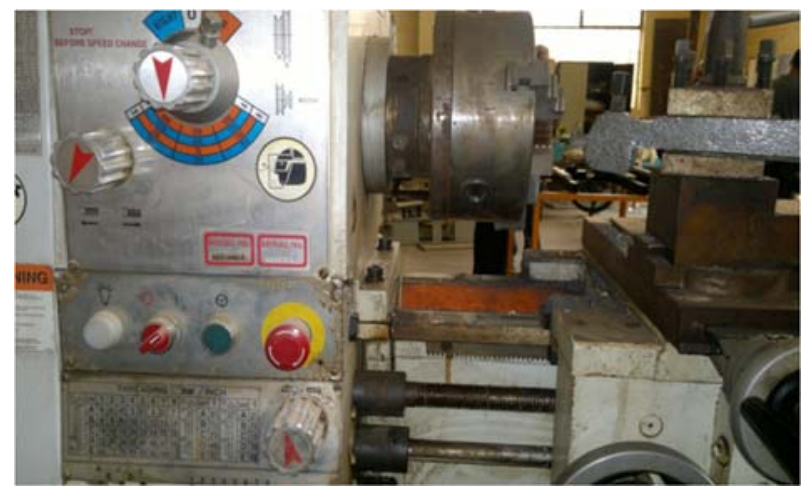

in diameter. Utilizing the PSG-A141 traditional lathe machine with an uncoated carbide insert tool, dry turning is performed on all workpieces as shown in figure 1 . For the experimental design, Taguchi's L27 orthogonal array is selected. The experiments are carried out by changing the process parameters and the mean surface roughness values $(\mathrm{Ra})$ with a sampling length of 5 mm were measured. Table 1 shows the considered cutting parameters and their levels.

Fig. 1. Turning process in experimental work.

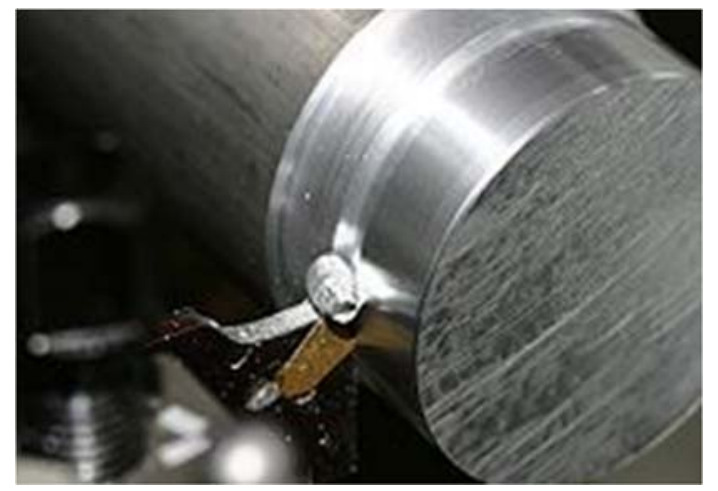

Table 1,

Control factors and levels

\begin{tabular}{lllll}
\hline Control Factors & Units & Level 1 & Level 2 & Level 3 \\
\hline Cutting speed, V & $\mathrm{rev} / \mathrm{min}$ & 355 & 230 & 150 \\
Feed rate, f & $\mathrm{mm} / \mathrm{min}$ & 0.3 & 0.13 & 0.07 \\
Cutting depth, d & $\mathrm{mm}$ & 0.6 & 0.4 & 0.2 \\
\hline
\end{tabular}

An experimental plan is needed to build a simulation model on the basis of the ANN that concerns to the average surface roughness and cutting parameters. Often, the classic experiment design is too complicated, considerable time, and difficult to use. Therefore, the Taguchi design of the experiment has been included in the current investigation. Three cutting parameters were considered, cutting speed (V), feed rate (f), and cutting depth (d). Based on the prior studies, the process parameter ranges were chosen. The process parameters were organized in the L27 Orthogonal Array of standard Taguchi. The twenty-seven pieces are machined utilizing the above set of values and surface roughness $(\mathrm{Ra})$ values are reported in Table 2 utilizing the microroughness tester TR220 as shown in figure 2.

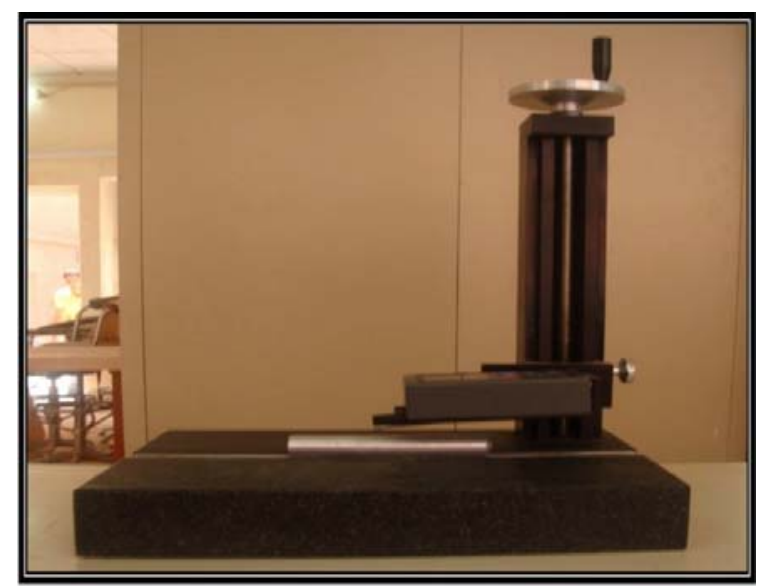

Fig. 2. TR220 micro roughness device when measuring surface roughness. 
Table 2,

Experimental values of surface roughness Ra.

\begin{tabular}{|c|c|c|c|c|}
\hline Exp. No. & $\begin{array}{l}\text { Cutting Speed (V) } \\
\text { rev/min }\end{array}$ & $\begin{array}{l}\text { Feed Rate (f) } \\
\mathrm{mm} / \mathrm{min}\end{array}$ & $\begin{array}{l}\text { Cutting Depth (d) } \\
\text { mm }\end{array}$ & $\begin{array}{l}\text { Roughness } \\
\text { (Experimental) } \mu \mathrm{m}\end{array}$ \\
\hline $\mathbf{1}$ & 355 & 0.3 & 0.6 & 2.577 \\
\hline 2 & 355 & 0.3 & 0.4 & 2.789 \\
\hline 3 & 355 & 0.3 & 0.2 & 2.89 \\
\hline 4 & 355 & 0.13 & 0.6 & 2.376 \\
\hline 5 & 355 & 0.13 & 0.4 & 2.949 \\
\hline 6 & 355 & 0.13 & 0.2 & 2.819 \\
\hline 7 & 355 & 0.07 & 0.6 & 2.14 \\
\hline 8 & 355 & 0.07 & 0.4 & 1.7545 \\
\hline 9 & 355 & 0.07 & 0.2 & 3.647 \\
\hline 10 & 230 & 0.3 & 0.6 & 2.464 \\
\hline 11 & 230 & 0.3 & 0.4 & 3.216 \\
\hline 12 & 230 & 0.3 & 0.2 & 3.53 \\
\hline 13 & 230 & 0.13 & 0.6 & 2.714 \\
\hline 14 & 230 & 0.13 & 0.4 & 2.975 \\
\hline 15 & 230 & 0.13 & 0.2 & 3.096 \\
\hline 16 & 230 & 0.07 & 0.6 & 2.3 \\
\hline 17 & 230 & 0.07 & 0.4 & 2.45 \\
\hline 18 & 230 & 0.07 & 0.2 & 3.8 \\
\hline 19 & 150 & 0.3 & 0.6 & 2.21 \\
\hline 20 & 150 & 0.3 & 0.4 & 2.813 \\
\hline 21 & 150 & 0.3 & 0.2 & 3.8 \\
\hline 22 & 150 & 0.13 & 0.6 & 2.161 \\
\hline 23 & 150 & 0.13 & 0.4 & 2.596 \\
\hline 24 & 150 & 0.13 & 0.2 & 3.711 \\
\hline 25 & 150 & 0.07 & 0.6 & 3 \\
\hline 26 & 150 & 0.07 & 0.4 & 3.4 \\
\hline 27 & 150 & 0.07 & 0.2 & 3.6 \\
\hline
\end{tabular}

\subsection{Artificial Neural Network (ANN)Model}

The input layer of ANN in this work has three neurons in terms of the three process parameters and one neuron in terms of surface roughness in the output layer. Different networks with different numbers of hidden layers and neurons in the hidden layer were constructed and verified to find the best network architecture; various training algorithms were utilized (Gradient descent, Newton method, Conjugate gradient, QuasiNewton, and Levenberg-Marquardt); log sigmoid transfer functions in the hidden layer and output layer were modified and the generalization

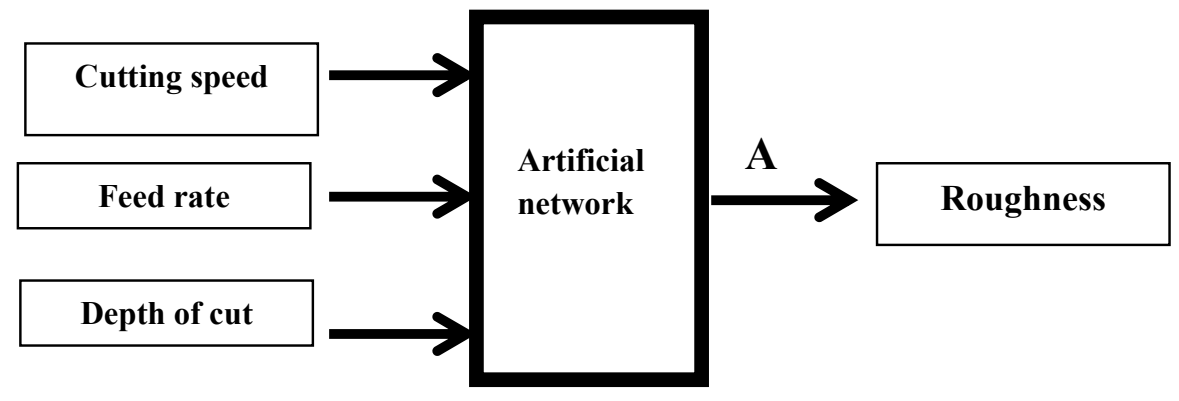

potential of the various networks was observed and eventually, the optimum network was chosen with best performance (minimum MSE) to precede.

The configuration of the ANN is indicated as 3-40-1, consisting of three input neurons; the hidden layer is composed of forty neurons, and the output layer composed of one output neuron, as shown in figure 3. After designing and examining several networks that differ in their structure, transfer mechanism, training algorithm, etc. The number of neurons in the hidden layer is calculated by the trial-and-error process.

Fig. 3. Neural network schematic diagram for Ra. 
Training of an ANN represents an essential task in the design of an estimation model. The reliability of the forecast relies on how well it has been trained. In the work, the training of the neural network was done utilizing a "feed-forward back-propagation algorithm". Two levels of data flow are carried out by the network. The input data is first spread from the input to the output layers and generates an output as a result. Then, the error signals arising from the disparity between the expected values of the networks and the real values are propagated back to the previous layers from the output layer to change their weights consequently. The weights upgrade continues till the objective of network error is achieved.

The number of neurons in the hidden layer is deliberately selected to begin with five neurons, and the hidden neurons are progressively added to the hidden layer. Until there is no substantial advance in network output, the addition of hidden neurons continues. In terms of network training, the network performance was assessed by mean square error (MSE) between the predicted and the experimental values for each output node. The feedback from that processing is called the "average error" or "performance". Since the average error is reached or below the needed target, the neural network stops training and is thus, ready to be confirmed. MATLAB is utilized to train the network architecture that are produced for surface roughness estimation.

The performance plot of the trained ANN model is shown in figure 4 . The best confirmation performance (MSE) of the ANN is identified as 0.00006497 which can be regarded as highly acceptable. The 27 patterns input-output dataset was split randomly into three categories: the training dataset consists of $50 \%$ of the data, the test dataset consists of $25 \%$ of the data, and the validation consists of $25 \%$ of the data. For ANN modeling of surface roughness, there are 13 training patterns considered. After training, the weights are frozen and the model is examined for confirmation. The network is confirmed in this work concerning the agreement with experimental outcomes.

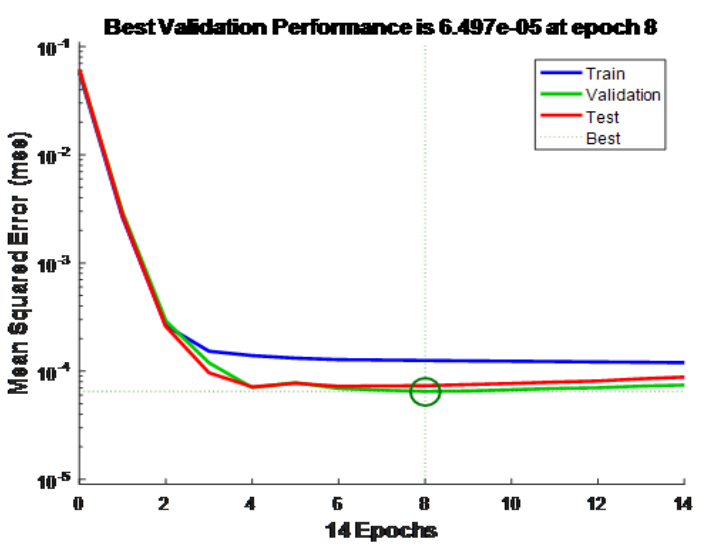

Fig. 4. Performance graph of the neural network after training.

\section{Results and Discussions 3.1 Experimental Analysis}

The experiment plan is designed to determine the impact of feed rate, cutting speed, and cutting depth on surface roughness Ra. This is observed in figure 5 where the surface roughness increases when the cutting speed increases from $150 \mathrm{rpm}$ to $350 \mathrm{rpm}$. The above pattern of rising the surface roughness with an increase in cutting speed is due to that the rate of heat transmitted to the surrounding from the machining area may be high. Therefore, the machining zone accumulates less heat. It is observed in figure 5 that as the feed rate increase from $0.07 \mathrm{~mm} / \mathrm{rev}$ to $0.3 \mathrm{~mm} / \mathrm{rev}$, the surface roughness steadily rising, due to the higher friction between cutting tool and work material as a result of greater cross-sectional area in the deformation region [19]. And it is also noted in the main impact plot in Fig. 5 that the surface roughness decreases as the cutting depth increases from $0.2 \mathrm{~mm}$ to $0.6 \mathrm{~mm}$ which is in agreement with Prasad et al. [19]. This can be assigned to the fact that a rise in cutting depth allows the temperature to increase due to an increase in frictional heat due to further contact between the working material and tool. Higher cutting temperatures, therefore, contribute to thermal softening of the working material, which leads less roughness of the metal [19]. Consequently, figure 5 and Table 2 show that machining with a cutting speed of $355 \mathrm{rpm}$ with a feed rate of $0.07 \mathrm{~mm} / \mathrm{rev}$ and a cutting depth of $0.4 \mathrm{~mm}$ achieved lower surface roughness. 

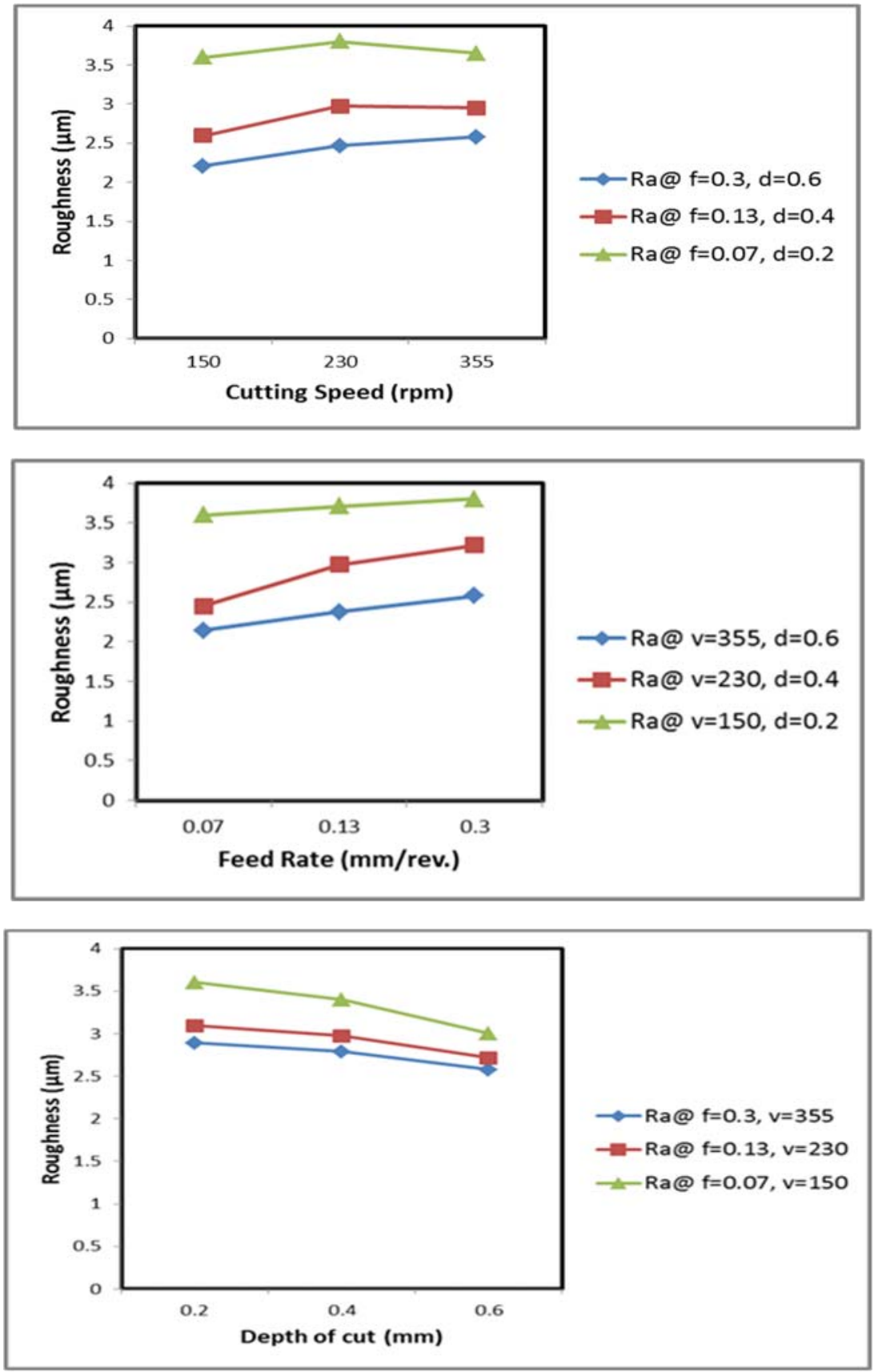

Fig. 5. Main effect plots of Ra.

\subsection{Artificial Neural Network Analysis}

The estimated values are obtained and error is determined for each data set as shown in Table 3. The estimated average percentage error is $3.64 \%$, indicating that the accuracy of the forecast is around $96 \%$. Figure 6 shows the plot of estimated surface roughness for different test cutting conditions utilizing the neural network and actual surface roughness. From the graphs, it is clear that for each of the output parameters, the suggested model can estimate values that are almost quite similar to experimental observations. The results show that the ANN model can be easily used to predict surface roughness and thus, assists in the optimal choice of process parameters $(\mathrm{V}, \mathrm{f}, \mathrm{d})$ for the planning of the cutting process and optimization of cutting parameters in turning DSS by uncoated carbide insert tool, which is agreed with Lavanya et al. [8]. 
Table 3,

Experimental and estimated surface roughness comparison

\begin{tabular}{|c|c|c|c|c|c|c|}
\hline Exp. No. & $\begin{array}{l}\text { Cutting } \\
\text { Speed (V) } \\
\text { rev/min }\end{array}$ & $\begin{array}{l}\text { Feed Rate (f) } \\
\mathrm{mm} / \mathrm{min}\end{array}$ & $\begin{array}{l}\text { Cutting } \\
\text { Depth (d) } \\
\text { mm }\end{array}$ & $\begin{array}{l}\text { Roughness } \\
\text { (Experimental) } \\
\mu \mathrm{m}\end{array}$ & $\begin{array}{l}\text { Roughness } \\
(\mathrm{ANN}) \\
\mu \mathrm{m}\end{array}$ & $\begin{array}{l}\text { Error } \\
\%\end{array}$ \\
\hline 1 & 355 & 0.3 & 0.6 & 2.577 & 2.66 & 3.22 \\
\hline 2 & 355 & 0.3 & 0.4 & 2.789 & 2.70 & 3.19 \\
\hline 3 & 355 & 0.3 & 0.2 & 2.89 & 2.97 & 2.76 \\
\hline 4 & 355 & 0.13 & 0.6 & 2.376 & 2.24 & 5.70 \\
\hline 5 & 355 & 0.13 & 0.4 & 2.949 & 2.93 & 0.64 \\
\hline 6 & 355 & 0.13 & 0.2 & 2.819 & 2.99 & 6.06 \\
\hline 7 & 355 & 0.07 & 0.6 & 2.14 & 1.97 & 7.94 \\
\hline 8 & 355 & 0.07 & 0.4 & 1.7545 & 1.83 & 4.3 \\
\hline 9 & 355 & 0.07 & 0.2 & 3.647 & 3.53 & 3.20 \\
\hline 10 & 230 & 0.3 & 0.6 & 2.464 & 2.49 & 1.05 \\
\hline 11 & 230 & 0.3 & 0.4 & 3.216 & 3.05 & 5.16 \\
\hline 12 & 230 & 0.3 & 0.2 & 3.53 & 3.73 & 5.66 \\
\hline 13 & 230 & 0.13 & 0.6 & 2.714 & 2.63 & 3.09 \\
\hline 14 & 230 & 0.13 & 0.4 & 2.975 & 3.08 & 3.52 \\
\hline 15 & 230 & 0.13 & 0.2 & 3.096 & 3.19 & 3.03 \\
\hline 16 & 230 & 0.07 & 0.6 & 2.3 & 2.40 & 4.34 \\
\hline 17 & 230 & 0.07 & 0.4 & 2.45 & 2.38 & 2.94 \\
\hline 18 & 230 & 0.07 & 0.2 & 3.8 & 3.64 & 4.21 \\
\hline 19 & 150 & 0.3 & 0.6 & 2.21 & 2.35 & 6.33 \\
\hline 20 & 150 & 0.3 & 0.4 & 2.813 & 2.76 & 1.88 \\
\hline 21 & 150 & 0.3 & 0.2 & 3.8 & 3.67 & 3.42 \\
\hline 22 & 150 & 0.13 & 0.6 & 2.161 & 2.21 & 2.26 \\
\hline 23 & 150 & 0.13 & 0.4 & 2.596 & 2.72 & 4.77 \\
\hline 24 & 150 & 0.13 & 0.2 & 3.711 & 3.71 & 0.02 \\
\hline 25 & 150 & 0.07 & 0.6 & 3 & 2.83 & 6.00 \\
\hline 26 & 150 & 0.07 & 0.4 & 3.4 & 3.28 & 3.52 \\
\hline 27 & 150 & 0.07 & 0.2 & 3.6 & 3.61 & 0.27 \\
\hline
\end{tabular}

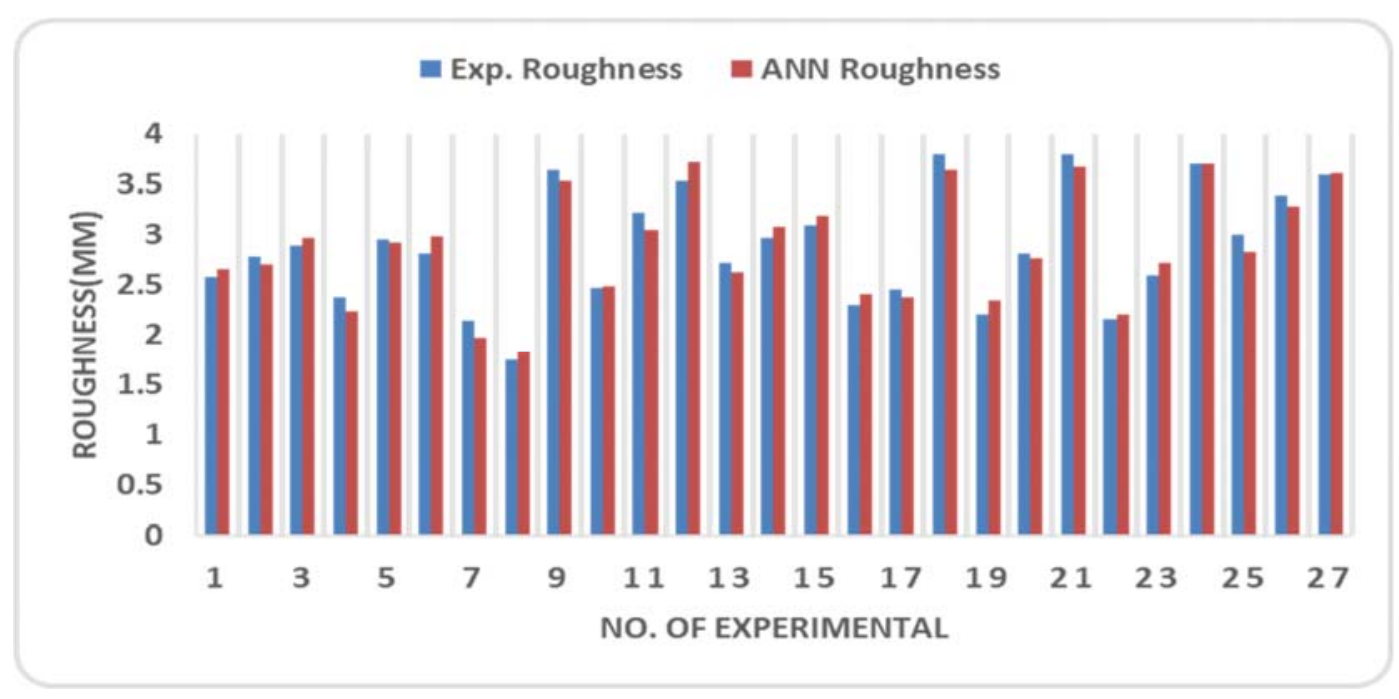

Fig. 6. Experimental and estimated surface roughness comparison at different cutting conditions. 


\section{Conclusions}

In the present study, the ANN model has been designed for surface roughness prediction in turning of DSS by utilizing the experimental results. The outcomes of the current work are outlined in the following:

- Machining at a cutting speed of $355 \mathrm{rpm}$ with a feed rate of $0.07 \mathrm{~mm} / \mathrm{rev}$ and a cutting depth of $0.4 \mathrm{~mm}$ has been found to achieve lower surface roughness.

- An increase in the cutting speed and feed rate increases the surface roughness, while an increase in the depth of cut reduces the surface roughness.

- The expected values obtained from ANN are similar to those obtained from experimental values. The outcome of the prediction is advantageous with a $3.64 \%$ average error, which means the neural network is capable of predicting up to $96 \%$ accurate surface roughness.

- It is also noted that ANN is a better model considering its speed, ease, and ability to learn from examples. It does not need more experimental investigation.

\section{References}

[1] J. Z. Zhang, J. C. Chen, and E. D. Kirby, "Surface roughness optimization in an endmilling operation using the Taguchi design method," Journal of materials processing technology, vol. 184, no. 1-3, pp. 233-239, 2007.

https://doi.org/10.1016/j.jmatprotec.2006.11. 029

[2] Kahraman, and A. Sagbas, "An investigation of the effect of heat treatment on surface roughness in machining by using statistical analysis," Iranian Journal of Science \& Technology, Transaction B: Engineering, vol. 34, no. B5, pp. 591-595, 2010.

[3] H. Gokkaya, and M. Nalbant, " The effects of cutting tool coating on the surface roughness of AISI 1015 steel depending on cutting parameters," Turkish Journal of Engineering and Environmental Sciences, vol. 30, no. 5, pp. 307-316, 2006.

[4] M. Nalbant, H. Gokkaya, and I. Toktas, "Comparison of regression and artificial neural network models for surface roughness prediction with the cutting parameters in CNC turning," Modeling and Simulation in Engineering, vol. 2007, pp. 1-14, 2007. https://doi.org/10.1155/2007/92717
[5] K. Palanikumar, and R. Karthikeyan, "Optimal machining conditions for turning of particulate metal matrix composites using Taguchi and response surface methodologies," Machining Science and Technology: An International Journal, vol.10, no. 4, pp. 417-433, 2007. https://doi.org/10.1080/10910340600996068

[6] A. Javidi, U. Rieger, and W. Eichlseder, "The effect of machining on the surface integrity and fatigue life," International Journal of Fatigue, vol. 30, no. 10-11, pp. 2050-2055, 2008. https://doi.org/10.1016/j.ijfatigue.2008.01.00 5

[7] H. Dave, L. Patel, and H. Raval, "Effect of machining conditions on MRR and surface roughness during $\mathrm{CNC}$ turning of different materials using TiN coated cutting tools- A Taguchi approach", International Journal of Industrial Engineering Computations, vol. 3, no. 5, pp. 925-930, 2012.

[8] K. Mani Lavanya, R. K .Suresh, A. Sushil Kumar Priya, and G. Krishnaiah, "Optimization of Process Parameters in Turning Operation of AISI-1016 Alloy Steels with CBN Using Artificial Neural Networks," International Journal of Engineering Trends and Technology (IJETT), vol. 5, no.6, pp. 294-297, 2013.

[9] G. Kant, and K. S. Sangwan, "Predictive modeling and optimization of machining parameters to minimize surface roughness using artificial neural network coupled with genetic algorithm," Procedia CIRP, vol. 31, pp. 453-458, 2015. https://doi.org/10.1016/j.procir.2015.03.043

[10] J. Vaibhav, and B. Sachin, "Process parameter optimization of CNC turning for titanium wrought iron," International Journal of Modern Trends in Engineering and Research, vol. 2, no. 11, pp. 141-146, 2015.

[11] B. Das, R. N. Rai, , and S.C. Saha, "Surface quality optimization of Al-5Cu alloy using utility theory coupled with the Taguchi method," Advances in Applied Physical and Chemical Sciences-A Sustainable Approach, vol. 2015, pp. 40-45, 2015.

[12] M. Gupta, and S. Kumar, " Investigation of surface roughness and MRR for turning UDGFRP using PCA and Taguchi method," Engineering Science and Technology, An International Journal, vol. 18, no. 1, pp. 7081 ,

2015. https://doi.org/10.1016/j.jestch.2014.09.006 
[13] P. Sonali, and A. M. Mohanty, " Performance analysis of surface roughness in al alloy using different cutting parameters," International Journal of Multidisciplinary Research and Development, vol. 3, no. 4, pp. 1-4, 2016.

[14] S. Dahbi, L. Ezzine, and H.E.L. Moussami, "Modeling of cutting performances in turning process using artificial neural networks," International Journal of Engineering Business Management, vol. 9, pp. 1-13, 2017. https://doi.org/10.1177\%2F18479790177189 88

[15] K. Pawan and J. P. Misra, "A Surface Roughness Predictive Model for DSS Longitudinal Turning Operation," Chapter 25 in DAAAM International Scientific Book, 2018, pp.285-296.

[16] Arjun Joshy, Royson Dsouza, Veerakumar Muthirulan1, and Krishnamurthy $\mathrm{H}$. Sachidananda, "Experimental Analysis on the Turning of Aluminum Alloy 7075 Based on Taguchi Method and Artificial Neural Network," Journal Européen des Systèmes
Automatisés, vol. 52, no. 5, pp. 429-437, 2019. https://doi.org/10.18280/jesa.520501

[17] R. Suresh, L. Shivaramu, N.G. Siddesh Kumar, T.N. Srikantha Dath, "Effect of Process Parameters on Cutting Forces and Surface Roughness in Machining of DSS 2205 Using Taguchi's Approach," Applied Mechanics and Materials, vol. 895, pp. 2631 , 2019. https://doi.org/10.4028/www.scientific.net/A MM.895.26

[18] Ahmed A. Elsadek, Ahmed M. Gaafer, and S.S. Mohamed, "Surface Roughness Prediction in Hard-Turning with ANN and RSM," Journal of The Egyptian Society of Tribology, vol. 17, no. 2, pp. 13-22, 2020.

[19] M. V. R. D. Prasad, Yelamanchili Sravya, and Karri Sai Tejaswi, "Study of the Influence of Process Parameters on Surface Roughness When Inconel 718 Is Dry Turned Using CBN Cutting Tool by Artificial Neural Network Approach," International Journal of Materials, Mechanics and Manufacturing, vol. 2, no. 4, pp. 335-338, 2014. 


\title{
التبؤ بخشونة سطح الفولاذ المقاوم للصدأ (DSS) بعد عملية الخراطة
}

\author{
أسامة فاضل عبداللطيف

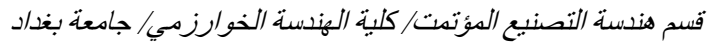 \\ البريد الإلكتروني:drosamah@kecbu.uobaghdad.edu.iq
}

الخلاصة

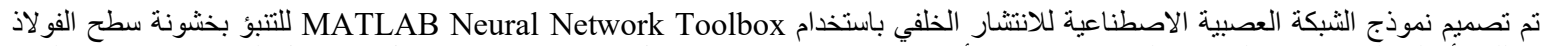

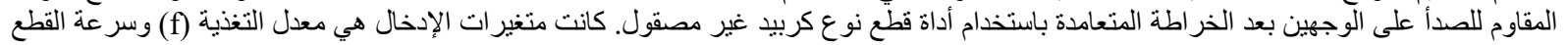

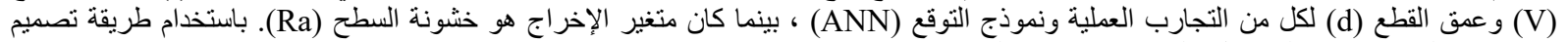

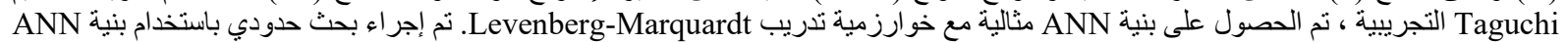

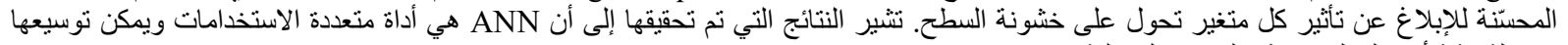

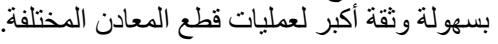

